\title{
A COMPETÊNCIA DO MUNICÍPIO PARA LEGISLAR SOBRE QUESTÕES AMBIENTAIS: A PROIBIÇÃO DA QUEIMA DA PALHA DA CANA-DE-AÇÚCAR
}

\author{
Paula Elizabete Antonini Joviano ${ }^{1}$ \\ Carlos Vitório Martins Joviano²
}

\begin{abstract}
RESUMO
A preocupação central deste artigo científico é a questão da competência municipal para legislar sobre questões ambientais. O delineamento metodológico a ser adotado é a pesquisa bibliográfica e documental, através de teorias de direito ambiental, teses e artigos científicos que desenvolveram os temas da expansão da cana-de-açúcar no Brasil, assim como os impactos ambientais resultantes da prática da queima da palha da cana nos canaviais e acórdãos do Supremo Tribunal Federal que trataram da competência municipal para proibir tal atividade, criando leis para abolir o emprego de fogo nos canaviais. O objetivo desta análise é demonstrar que a Constituição de 1988 conferiu o dever de proteção e defesa do meio ambiente local ao Município, podendo este ente federativo criar leis com a finalidade de resguardar os aspectos sociais e ambientais que surgem com a prática de atividades nocivas ao meio ambiente, que não sejam socialmente justas e que afetem a saúde da população local. Iniciou-se o estudo desenvolvendo a descrição da expansão da cana-de-açúcar no Brasil, assim como os problemas ambientais que surgiram com as queimadas da cana-de-açúcar resultantes da liberação do gás carbônico e de outros compostos nitrogenados. Finalizando a pesquisa, concluiu-se que a participação do Município seria muito importante para efetivar a proteção ambiental local, já que este está próximo à realidade da região, cabendo à administração municipal legislar com coerência, tendo como finalidade proporcionar o meio ambiente ecologicamente equilibrado aos habitantes de determinada localidade.
\end{abstract}

PALAVRAS-CHAVE: Cana de açúcar, Impactos ambientais, Município.

\section{THE JURISDICTION OF THE MUNICIPALITY TO LEGISLATE ON ENVIRONMENTAL ISSUES : THE PROHIBITION OF STRAW BURNING OF SUGARCANE}

\begin{abstract}
The central concern of this scientific paper is the issue of municipal competence to legislate on environmental issues. The methodological design to be adopted is the bibliographical and
\end{abstract}

\footnotetext{
${ }^{1}$ Advogada, especialista em Direito do Estado pela Universidade Estadual de Londrina. E-mail: paulajoviano@gmail.com

2 Mestre em Geografia pela Universidade Federal da Grande Dourados. E-mail: carlosjoviano@hotmail.com
} 


\section{Periódica Eletrânica \\ Fórum Ambiental}

da Alta Paulista
Volume 11, Número 02, 2015

Campo, Agronegócio

e as Práticas Sustentáveis

documentary research, through environmental law doctrines, theses and research papers that have developed the issues of expansion of sugarcane in Brazil, as well as the environmental impacts resulting from the practice of burning Straw cane in the cane fields and judgments of the Supreme Court that dealt with the municipal power to prohibit such activity, creating laws to abolish the fire employment in the fields. The purpose of this analysis is to demonstrate that the 1988 Constitution conferred the duty of protection and defense of the local environment to the municipality, which may federative entity create laws in order to protect the social and environmental aspects that come with the practice of harmful activities to environment, they are not socially fair and affecting the health of local people. It began the study developing the description of the expansion of sugarcane in Brazil, as well as environmental problems arising from the burning of sugarcane resulting from the release of carbon dioxide and other nitrogen compounds. Finishing the research, it was concluded that the participation of the municipality would be very important to carry out the local environmental protection, since this is close to the reality of the region, while the municipal administration legislate coherently, with the purpose to provide the ecologically balanced environment to inhabitants of a given locality.

KEYWORDS: Sugarcane, environmental impacts, Municipality

\section{LA JURISDICCIÓN DEL MUNICIPIO DE LEGISLAR SOBRE CUESTIONES AMBIENTALES: LA PROHIBICIÓN DE LA QUEMA DE LA PAJA DE LA CAÑA DE AZÚCAR}

\section{RESUMEN}

La preocupación central de este trabajo científico es la cuestión de la competencia municipal para legislar sobre cuestiones ambientales. El diseño metodológico que se adoptará es la investigación bibliográfica y documental, a través de las doctrinas de derecho ambiental, tesis y trabajos de investigación que se han desarrollado los temas de la expansión de la caña de azúcar en Brasil, así como los impactos ambientales resultantes de la práctica de la quema caña de paja en los campos de caña y las sentencias del Tribunal Supremo que trataba el poder municipal para prohibir dicha actividad, la creación de leyes para abolir el empleo de fuego en los campos. El propósito de este análisis es demostrar que la Constitución de 1988 confirió el deber de protección y defensa del medio ambiente local para el municipio, que puede Entidad Federativa crear leyes para proteger a los aspectos sociales y ambientales que vienen con la práctica de actividades nocivas para medio ambiente, que no son socialmente justo y que afectan a la salud de la población local. Comenzó el estudio el desarrollo de la descripción de la expansión de la caña de azúcar en Brasil, así como los problemas ambientales derivados de la quema de la caña de azúcar como consecuencia de la liberación de dióxido de carbono y otros compuestos de nitrógeno. Finalización de la investigación, se concluyó que la participación del municipio sería muy importante para llevar a cabo la protección del medio ambiente local, ya que se trata de cerca de la realidad de la región, mientras que la administración municipal legislar de manera coherente, con el fin de proporcionar el medio ambiente ecológicamente equilibrado habitantes de una localidad determinada.

PALABRAS CLAVE: Caña de azúcar, impactos ambientales, Municipio 


\section{INTRODUÇÃO}

Com a expansão da cana de açúcar no Brasil, especialmente na região Centro-Oeste, houve notável avanço socioeconômico, ocasionando grande crescimento de área plantada nos Estados de São Paulo, Minas Gerais, Goiás, Mato Grosso do Sul, Mato Grosso e Paraná, e a implantação de usinas de álcool nas regiões mencionadas, sendo o Estado de São Paulo o maior produtor de cana-deaçúcar do país.

Contudo, na análise de alguns aspectos ambientais do desenvolvimento do setor sucroalcooleiro da cana-de-açúcar, percebeu-se que tal atividade empresarial não traz somente benefícios, mas também gera uma série de questões ambientais que surgem com a queima da palha da cana-de-açúcar.

$\mathrm{Na}$ intenção de se facilitar a colheita, as folhas secas e verdes (descartáveis) são queimadas, ou seja, ateia-se fogo no canavial. Tal prática se tornou extremamente nociva ao meio ambiente local e à população do Município, pois neste processo há emissão de gases do efeito estufa na atmosfera (essencialmente o gás carbônico, monóxido de carbono, óxido nitroso, metano e ozônio).

Desta problemática, surgiu o questionamento acerca da possibilidade de o Município criar leis que proibissem práticas que atentassem ao meio ambiente, ou seja, legislar em favor do meio ambiente local.

Analisando a repartição das competências constitucionais para legislar sobre matérias constitucionais, identifica-se que o Município foi dotado de autonomia na Constituição Federal de 1988, que ampliou suas competências e conferiu-lhe a competência privativa para tratar de questões ambientais locais.

Neste sentido, a indagação a respeito da possibilidade de se legislar em favor do Município passou a depender de opiniões contraditórias: alguns magistrados alegam a inconstitucionalidade formal das leis editadas pelos Municípios. Eles afirmam que a competência para tal questão seja exclusiva dos Estados e da União, portanto a lei do Município que proíba afrontas ao meio ambiente local que seja contrária à autorização expressa na Lei Estadual é inconstitucional.

Ainda que parte dos Desembargadores tenha entendido que a possibilidade do Município criar leis sobre questões ambientais já tratadas pelos Estados seja 
restrita, existe parte dos magistrados que compreendem a necessidade do Município tutelar pelo meio ambiente local.

Existe a previsão de competência do Município para legislar sobre diversos assuntos específicos, descritos no artigo 30 , da Constituição Federal, sendo estes: assuntos de interesse local; suplementar a legislação federal e estadual no que couber; promover, no que couber adequado ordenamento territorial, mediante planejamento e controle de uso, do parcelamento e da ocupação do solo.

No caso em discussão, a questão abordada foi a possibilidade de o Município criar leis que proíbam a queima da palha da cana-de-açúcar, já que restou evidente os gravíssimos impactos ambientais de tal prática.

Coube ao Poder Judiciário resolver tal demanda, com proporcionalidade, atendendo aos valores ambientais que devem ser tutelados por todos os entes federativos. A decisão dos Desembargadores será crucial ao desenvolvimento desta temática, pois influenciará diversas ações de inconstitucionalidade referentes à queima da cana-de-açúcar que surgirão.

\section{OBJETIVOS}

O objetivo desta análise é identificar a expansão da cana-de-açúcar no território brasileiro, contrapondo os benefícios econômicos da atividade empresária de biocombustíveis aos graves impactos ambientais resultantes da queima da palha da cana.

Posteriormente, visa-se demonstrar que a Constituição de 1988 conferiu o dever de proteção e defesa do meio ambiente local ao Município, podendo este ente federativo criar leis com a finalidade de resguardar os aspectos sociais e ambientais que surgem com a prática de atividades nocivas ao meio ambiente, que não sejam socialmente justas e que afetem a saúde da população local.

\section{METODOLOGIA}

Os procedimentos a serem seguidos na realização deste projeto pautam-se nos moldes da pesquisa de natureza explicativa e o tipo de delineamento metodológico a ser adotado é a pesquisa bibliográfica e documental. 
Ademais, utilizar-se-á a pesquisa empírica já que haverá a busca de dados convenientes à temática em análise, precisamente, o estudo da expansão da canade-açúcar no Brasil, assim como dos impactos ambientais causados pela queima da palha da cana e o questionamento acerca da possibilidade de o Município editar leis que tenham a finalidade de proteger o meio ambiente local.

A análise dos dados presentes neste projeto se dará de forma qualitativa, utilizando-se do método indutivo, através da apreciação do conteúdo estudado nesta pesquisa.

A questão da competência do Município para legislar acerca de matérias ambientais é a preocupação central deste estudo e será exposta de maneira a delimitar a hipótese da pesquisa documental e bibliográfica através de doutrinas de direito ambiental, da delimitação de competências da União, do Estado e dos Municípios presente na Constituição Federal de 1988, e de autores que trate da temática do desenvolvimento da cana-de-açúcar no Brasil e os impactos das queimadas da palha da cana no meio ambiente.

\section{RESULTADOS}

\section{1 - EXPANSÃO DA CANA DE AÇUCAR NO BRASIL}

Sabe-se que o Brasil é o maior produtor de cana de açúcar e maior exportador de açúcar no mundo, setor este que gera mais de dois bilhões de dólares por ano na balança comercial brasileira.

Segundo Joviano (2009), a territorialização do setor canavieiro para produção de etanol ocorreu em duas fases: a primeira fase teve início no final da década de 1970, em decorrência da atuação do Estado no incentivo à produção de álcool, quando passou a exercer uma política intervencionista, ao lançar medidas que resultaram na criação do Programa Nacional do Álcool (Proálcool), que entre os vários interesses abria a possibilidade de obter combustíveis alternativos para amenizar a crise do petróleo de 1973; e a segunda a partir do ano de 2001, com a revitalização do consumo de álcool etílico como bioenergia, devido a maior conscientização do Protocolo de Kyoto que propõe aos países desenvolvidos a redução dos níveis de emissão de dióxido de carbono. 
Dessa forma, na tentativa de obter resultados rápidos, descobrindo uma opção energética renovável que substituísse o consumo de gasolina e atenuasse os efeitos negativos da crise do petróleo de 1973, o governo brasileiro criou o Programa Nacional do Álcool - PROÁLCOOL - instituído em 1975, com os objetivos de diminuir a dependência da importação de petróleo, economizar divisas e alargar para o interior o desenvolvimento agroindustrial gerando emprego e renda, (JOVIANO, 2009).

Segundo Joviano (2009):

\begin{abstract}
A atuação do Estado foi de suma importância para impulsionar o consumo de álcool, pois na tentativa de encontrar uma alternativa energética renovável para substituir o petróleo, o governo brasileiro adota algumas medidas para motivar a opinião pública e incentivar os investidores do setor canavieiro, tais como: estabelecer em $20 \%$ a mistura de álcool anidro ${ }^{3}$ à gasolina; priorizar o uso de veículo a álcool na frota nacional; diminuir a alíquota de Imposto sobre Produto Industrializado (IPI) e Taxa Rodoviária Única (atual IPVA) para veículos movidos a álcool; isentar o IPI para táxis a álcool; aumentar a revenda de álcool hidratado com preço estipulado em no máximo de $65 \%$ do preço da gasolina; estabelecendo uma série de incentivos públicos fiscais e financeiros aos produtores de álcool (anidro e hidratado) para a da instalação de destilarias anexas às usinas de açúcar e para a implantação de destilarias autônomas. (JOVIANO, 2009, p. 134).
\end{abstract}

Portanto, o programa surgiu estruturado em subsídios e financiamentos públicos, ficando sob a responsabilidade da estatal PETROBRAS, a compra, o transporte, o armazenamento, a distribuição, a mistura do álcool na gasolina, e também a decisão do preço de venda do produto.

Para Thomaz Junior (2002, p. 76) este programa "resultou no fortalecimento de uma relação secular de privilégios e favores especiais. Isto é, nascido em berço esplêndido, o Proálcool selou a mediação estatal na atividade sucroalcooleira". Os incentivos do Programa Nacional do Álcool, em 1975, trouxeram como consequência o rápido desenvolvimento das agroindústrias sucroalcooleiras, que, articuladas ao setor automobilístico, expandiam-se assustadoramente:

O Proálcool se materializou organicamente em escala nacional quando se articulou ao setor automobilístico, apresentando-se, então, o álcool como alternativa a gasolina. Assim cimentaram-se os interesses do capital

3 O álcool adicionado à gasolina é denominado álcool etílico anidro combustível (AEAC) e desde 1979 seus teores de adição sofrem frequentes alterações devido a demandas de mercado no setor de álcool e açúcar. Já o álcool comercializado nos postos de revenda de combustível é denominado álcool etílico hidratado combustível (AEHC). 
agroindustrial sucroalcooleiro, com os segmentos das indústrias multinacionais, montadoras de automóveis, (...), fábricas de tratores implementos agrícolas, (...) Pode-se dizer que foi uma solução para os grandes empresários, principalmente os do Centro Sul, em especial para os paulistas, recuperarem o padrão de acumulação do capital, até pelo fato de terem sido os atores ativos na criação e consolidação do Programa. (THOMAZ JUNIOR, 2002, p. 93).

Com relação ao crescimento da produção sucroalcooleira o mesmo autor afirma que:

(...) o setor sucroalcooleiro cresceu a uma taxa de $35 \%$ / ano no período compreendido entre 1975/86 e, só em São Paulo, alcançou 36\% / ano (...) não foi capaz de evitar o processo de expansão da cana de açúcar sobre as culturas alimentares e consequentemente o ritmo concentrador de terras nas áreas tradicionais sob comando das maiores empresas sucroalcooleiras (THOMAZ JUNIOR, 2002, p. 95 e 98).

Nessa conjuntura, Thomaz Junior (2002) afirma que a expansão setor sucroalcooleiro se deu devido à facilidade de conseguir crédito, através dos financiamentos e incentivos do Estado como subsídios, redução de alíquota de Imposto e os financiamentos aos produtores de álcool, porém dentre estes os financiamentos estavam entre os incentivos mais atraentes.

As taxas de juros estabelecidas nesse momento foram de 17\% ao ano para o financiamento do parque industrial do Centro Sul e 15\% para o Norte e Nordeste, num período em que a inflação situava-se em tomo de $37 \%$ ano e o financiamento cobria $100 \%$ do empreendimento em todo o país, sem haver necessidade de contrapartida do empresário, com prazos de 12 anos para pagamento e três de carência. (THOMAZ JUNIOR, 2002, p, 90)

Assim, o plano do Governo Federal quanto ao Proálcool foi inicialmente de modernizar e implantar usinas de álcool anexas às usinas de açúcar já existentes, objetivando o aumento da produção de álcool anidro para ser misturado à gasolina, num percentual de $20 \%$ a $22 \%$ e posteriormente expandir o número de destilarias autônomas, pois com a continuação da crise do petróleo era substituir parte da gasolina utilizada na frota nacional de veículos de passageiros por álcool, ou seja, era preciso aumentar a produção de álcool hidratado para abastecer veículos com motores movidos a álcool, (JOVIANO, 2009).

Diante do sucesso do Programa e o apoio do Estado, o Governo Federal fechou um acordo com as indústrias automobilísticas para iniciarem a fabricação de 
carros movidos a álcool, necessitando para isso apoiar a implantação de novas destilarias para aumentar a produção de álcool, a partir de 1980. Com isso, as montadoras de automóveis aumentaram a produção de carros a álcool, chegando em 1985 a 95\% da frota brasileira de veículos e utilitários:

\begin{abstract}
Mas, se aumentou a produção de carro a álcool a produção de combustível para estes carros aumentou mais ainda, e ante tal aumento de produção ocorreu um descompasso entre a oferta e o consumo, ocasionando um excedente de álcool, obrigando o governo a buscar uma solução através da exportação do produto. Porém, a partir de 1985, a cotação do açúcar começa a aumentar no mercado internacional, o que fez com que o setor sucroalcooleiro usasse suas estruturas para a produção de açúcar no lugar do álcool, mostrando a fragilidade do sistema e como resultado teve a falta de álcool hidratado nas bombas dos postos de combustível, balançando seriamente a confiança do consumidor em relação ao Proálcool. Assim, como as indústrias usavam os benefícios do Estado, mas não estavam produzindo combustível, o Governo Federal é forçado a rever as políticas que materializaram o molde de desenvolvimento do setor canavieiro através do Proálcool, decretando a redução das políticas paternalistas e protecionistas dos empréstimos subsidiados, dos perdões de dívidas, dos incentivos para produção e das garantias de mercado e preços aos produtos da cana-de-açúcar. (JOVIANO, 2009, p. 134).
\end{abstract}

Contudo, essas ações do governo trouxeram como consequência a falência de várias destilarias e a diminuição drástica da produção de carros movidos a álcool por parte das montadoras de automóveis.

Contudo, a partir de 2001, com o aumento do consumo interno e da exportação do açúcar e do álcool (anidro e hidratado), particularmente para o abastecimento do mercado interno, ocorre a segunda fase da territorialização do setor sucroalcooleiro, impulsionada pelas oscilações e aumento dos preços do petróleo devido às tensões na região do Oriente Médio; a busca por fontes energéticas renováveis; o aproveitamento do bagaço na energia e o vinhoto para fertilização por irrigação; o crescimento na demanda de álcool motivada pela produção de veículos bicombustível e do aumento de consumo de açúcar e álcool em países como China e Índia; questões ambientais que colocam a necessidade de substituição de derivados de petróleo para evitar as emissões de gases estufas, (JOVIANO, 2009).

Apesar da crise, o Programa Nacional de Álcool fez com que o Brasil se tornasse referência na produção de álcool combustível, pois o país já conseguiu substituir em torno de $45 \%$ do mercado de gasolina pelo agrocombustível, enquanto 
que nos EUA, ainda não foram substituídos nem 3\% do consumo. Estima-se que para substituir $10 \%$ da gasolina consumida no mundo por etanol brasileiro, a atual área plantada que é de aproximadamente 9,0 milhões de hectares deverá quadruplicar, (JOVIANO, 2009).

Contudo, isso só foi possível com os programas de governo e através do melhoramento genético, a cana-de-açúcar revolucionou a produção de bicombustíveis, já que se revelou como a grande inovação do cenário energético quando a questão é sustentabilidade, e, economicamente, trouxe considerável redução nos custos e aumentou a eficiência da produção.

O Brasil alavancou-se numa situação privilegiada, estando na vanguarda mundial da biotecnologia de cana, desencadeando no aumento da produtividade canavieira, e na resistência do plantio às pragas, doenças e variações climáticas, considerando a grande diversificação de variedades do cultivo da cana. (GOES, 2008, p.1)

Outro fator que contribuiu para o crescimento econômico brasileiro relacionado ao plantio de cana-de-açúcar, essencialmente interligado à produção energética do etanol da cana, foram as condições climáticas e do solo, tornando o Brasil uma superpotência na produção de alimento e energia. (KOHLHEPP, 2010, sem paginação)

Aliada à sustentabilidade da produção canavieira, outro benefício da produção de etanol é a incidência de ocupação de terras produtivas destinadas ao cultivo canavieiro, que é de apenas $1 \%$.

Sinteticamente, pode-se afirmar que o Brasil cresceu progressivamente na produção canavieira e que tal atividade econômica influiu diretamente no desenvolvimento de biocombustíveis no país através do etanol, sendo exercida principalmente na região Centro-Sul do Brasil, trazendo maior sustentabilidade e maior produtividade ao setor energético. Apesar de que este tipo de produção é feito através do agronegócio e o agronegócio e, não é um fenômeno novo, mas herdeiro do antigo latifúndio com origem no sistema de plantation em grandes propriedades, utilizadas na produção para exportação. Para Fernandes (2005), o Agronegócio é a nova denominação de uma velha estrutura, "é uma palavra nova, da década de 
1990, e é também uma construção ideológica para tentar mudar a imagem latifundista da agricultura capitalista" (FERNANDES, 2005, p. 01).

Podemos dizer que tal atividade tem se qualificado como uma das formas de territorialização do capital no campo mais cruéis, onde ocorre a ratificação e a montagem de estratégias que avalizam a sua hegemonia sobre o território e que esta territorialização se dá pelo controle da terra pelo capital

Essas ponderações nos auxiliam a compreender 0 processo de territorialização do capital sucroalcooleiro, pois a incorporação do território no âmbito das relações capitalistas de produção imprime um processo de territorialização a partir do interesse capitalista sobre terras que antes fazia-se agricultura de subsistência, portanto o termo sustentabilidade deve ser entendido somente numa comparação entre o uso de combustíveis etanol-gasolina, mas não em uma comparação entre agronegócio - agroecologia.

\section{2 - IMPACTOS AMBIENTAIS DA QUEIMA DA PALHA DA CANA DE AÇÚCAR}

O principal problema ambiental gerado pelo setor da cana-de-açúcar a ser tratado é a queima da palha da cana-de-açúcar.

Por serem consideradas matérias primas descartáveis, as folhas secas e verdes são queimadas, ateando-se fogo no canavial, com a finalidade de se facilitar a colheita, emitindo gases do efeito estufa na atmosfera (essencialmente o gás carbônico, monóxido de carbono, óxido nitroso, metano e ozônio), como afirma Goldemberg:

\footnotetext{
A queima de combustíveis fósseis produz enormes quantidades de dióxido de carbono (CO2). Esta é uma das maiores fontes de emissões de 'gases do efeito estufa', que estão alterando a composição da atmosfera e podem gerar mudanças climáticas globais, incluindo a quantidade e composição da chuva". (GOLDEMBERG, 2003, p. 174).
}

Porém, constata-se que há proporção de emissão de $9 \mathrm{~kg}$ de gás carbônico para cada tonelada de cana com a queima da palha da cana-de-açúcar, já a fotossíntese da cana retira aproximadamente 15 toneladas de gás carbônico por hectare, ou seja, o plantio da cana-de-açúcar absorve mais carbono do que absorve na atmosfera, apresentando, desta forma um balanço positivo. 
O impacto no meio ambiente causado pelas queimadas se dá coma liberação do gás carbônico absolvido pela cana durante seu período de crescimento, que dura de 12 a 18 meses. Há ainda a liberação de fumaça e fuligem, poluindo o ar atmosférico.

\footnotetext{
As grandes cidades eram apontadas como responsáveis por ter a quantidade de ar deteriorada, por conta das suas atividades, da aglomeração de pessoas e construções. No entanto, a contribuição para a deterioração da quantidade do ar não advém apenas dos grandes centros; mas também, por exemplo, no cultivo da cana, onde há o processo de queima da cultura para a colheita. (SILVEIRA, 2014, p.16)
}

Além do impacto ambiental causado na queima da cana nos canaviais, há alteração do meio ambiente da população que vive nas proximidades das indústrias que utilizam a cana-de-açúcar como matéria-prima.

A indústria de cana de açúcar envolve uma série de mudanças na vida da população que vive próxima à sua produção, na dinâmica regional política e econômica, além de impactar o meio ambiente. (SILVEIRA, 2014, p.31)

Além da liberação do gás carbônico, há ainda a liberação de compostos nitrogenados (emissão de óxido nitroso) responsáveis por causar desastres ambientais como a chuva ácida, contaminando a água e o solo, podendo interferir na biodiversidade, matando os peixes e provocando declínio em florestas naturais. (AIRES; KIRCHHOFF, 2000, p.16).

O ozônio liberado na atmosfera é tóxico na baixa atmosfera e prejudica o crescimento das plantas e a vida animal e humana. Nos seres humanos a emissão do gás de ozônio pode acarretar em sérios problemas respiratórios, assim como irritações nos olhos e infecções, pois diminui a resistência do organismo. (MATTOS, 2002, p.154).

O problema ambiental gerado pela queima da cana sob a ótica agronômica tem como conclusão que o solo fica prejudicado quando há intensas queimadas, o que pode influenciar em sua fertilidade.

Além do solo, há também oxidação de matéria orgânica, eliminam-se os predadores naturais de pragas, o que leva o agricultor a utilizar mais agrotóxicos e herbicidas (já que ervas daninhas se desenvolvem com facilidade após a queimada), 
o processo de erosão do solo é agravado, pois não há cobertura vegetal no solo e se diminui o equilíbrio ecológico, já que pequenos animais são queimados no processo de queima da cana. (AZANIA, 2012, não paginado)

No aspecto econômico da queima da cana-de-açúcar, pode-se afirmar que tal procedimento faz com que a colheita seja mais fácil e barata, mas pode causar prejuízo se houver atraso no corte, além da questão do tratamento de água da lavagem pelo aumento de volume necessário.

Não obstante, referente à questão energética da queima da cana, calcula-se que $30 \%$ da matéria prima da cana poderia ser aproveitada na produção de biogás, ou gerando energia de biomassa, ao ser utilizada em caldeias. (AZANIA, 2012, não paginado)

\section{3 - COMPETÊNCIAS DO MUNICÍPIO PARA LEGISLAR MATÉRIAS AMBIENTAIS PREVISTAS NA CONSTITUIÇÃO FEDERAL DE 1988}

Considerando a análise constitucional da competência dos municípios em matéria ambiental, pode-se afirmar a constitucionalidade da atuação do Município quando legislem favor das demandas ambientais locais de maneira suplementar a competência da União e dos Estados, respaldado no princípio da predominância do interesse e no princípio da subsidiariedade.

Portanto, resta questionar em que situações o município pode atuar em favor do meio ambiente, coibindo práticas que sejam causadoras de danos ambientais, regulando matérias que não sejam proibidas pela União ou pelo Estado, considerando questões de interesse local.

A competência municipal para tratar de "assuntos de interesse local" é privativa, na medida em que houve considerável ampliação das competências do município, sendo que este recebeu o status de ente da Federação na Constituição de 1988 e passou a ter maior autonomia gradativamente. É evidente o reconhecimento de tal atuação municipal que rompeu com a política centralizadora de competências brasileiras, como argumenta Arthur Antônio Barbosa: 


\begin{abstract}
"assuntos de interesse local", assegurou-lhe a possibilidade de suplementação das leis estaduais e federais, bem como the impôs a competência comum de proteção do meio ambiente e do combate à poluição. (BARBOSA, 2013, p. 12).
\end{abstract}

Nesta perspectiva, a participação do Município seria muito importante para efetivar a proteção ambiental local, já que este está próximo à realidade da região, cabendo à administração municipal legislar com coerência, tendo como finalidade proporcionar o meio ambiente ecologicamente equilibrado aos habitantes de determinada localidade.

Porém, em que pese a possibilidade do Município legislar em favor do meio ambiente pareça ser uma boa solução para proteger ambiente local, há ainda resistência dos membros do Poder Judiciário sobre tal possibilidade, alegando a inconstitucionalidade de várias leis ambientais editadas pelo Município por falta de competência deste para coibir atividades que não são proibidas pela legislação estadual e federal.

Ainda assim, a posição dos magistrados tem se flexibilizado gradativamente em favor da atuação municipal na defesa do meio ambiente local, como afirma Arthur Antônio Barbosa:

\begin{abstract}
Por outro lado, pode-se enxergar uma mudança dessa jurisprudência centralizadora, notadamente pela sensibilidade demonstrada por parte dos Ministros do Supremo Tribunal Federal, assim com o por alguns votos dos Desembargadores do Tribunal de Justiça do Estado de São Paulo. Como será demonstrado, hoje já existem importantes precedentes a favor da competência legislativa dos entes municipais. (BARBOSA, 2013, p. 13)
\end{abstract}

Tal questão deve ser interpretada sob a ótica da supremacia das normas constitucionais, ou seja, a análise da constitucionalidade das leis editadas pelo Município deve se pautar em harmonizar tais leis com os ditames constitucionais.

Neste sentido, se a Constituição Federal confere ao Município o comando normativo constitucional de propiciar à coletividade o meio ambiente ecologicamente equilibrado, como consta em seu artigo 225, cabe a este zelar pelas matérias ambientais de sua localidade, legislando e cumprindo seu dever constitucional.

A discussão a respeito da competência municipal, conclui-se que deverá existir mútua contribuição dos entes federados, possibilitando a proteção do meio 
ambiente local e a concordância das normas de competência presentes na Constituição.

\section{4 - A INTERFERÊNCIA DOS MUNICÍPIOS NO CASO DA QUEIMA DA PALHA DA CANA-DE-AÇÚCAR}

A queima da palha da cana-de-açúcar é uma prática altamente poluidora e nociva ao meio ambiente, tema já abordado nesta pesquisa, e se sabe que as queimadas dos canaviais podem oferecer riscos à saúde da população local.

Se a Constituição for interpretada sob a ótica do dever constitucional do Município de proteger o meio ambiente local, é evidente que o Município que venha a sofrer os impactos ambientais resultantes da queima da palha da cana possa criar leis que proíbam tal prática, pois tal atuação é plausível e justificada.

Porém, nem todas as decisões judiciais acerca desta temática são favoráveis à competência legislativa do Município para editar leis que proíbam a queima da cana-de-açúcar, sob o argumento de que tais leis sejam inconstitucionais e ferem a divisão de competências legislativas estabelecida pela Constituição de 1988.

A análise dos casos julgados nesta matéria revela que não há decisão unânime ao se tratar da interferência do Município na questão da edição de leis proibitivas à queima da palha da cana.

Alguns magistrados entendem que a legislação municipal não deve usurpar a competência legislativa da União e dos Estados, e se houver a criação de leis municipais que proíbam alguma prática que esteja autorizada pela legislação estadual ou federal, formalmente, a lei municipal seria inconstitucional.

Contudo, como já foi mencionado, tal entendimento não foi pacificado, inclusive, busca-se que não haja disparidade de legislação, pois os posicionamentos são diversos, porém seria viável se houvesse a uniformização das práticas dos municípios.

No Estado de São Paulo, o município de Cedral, foi um exemplo do debate acerca da proibição do Município de se utilizar do emprego do fogo para queimar os canaviais. 
O Desembargador Luiz Elias Tamabra afirmou que o emprego do fogo foi minuciosamente disciplinado através de normas editadas pela União e pelo Estado de São Paulo, que possuíam competência exclusiva conferida na Constituição Federal para tratar da matéria.

José Afonso da Silva esclarece que: "a diferença que se faz entre competência exclusiva e competência privativa é que aquela é indelegável e esta é delegável". Portanto, nesta perspectiva, o Município não teria competência para legislar sobre questões ambientais, e não deveria afrontar qualquer lei editada pelos Estados ou pela União. (SILVA, 2014, p. 478).

$\mathrm{Na}$ opinião de Luiz Elias, o Município deveria tão somente suplementar a legislação já existente, ou seja, a legislação federal e estadual, no que couber. Nesta visão predomina-se a ideia de que apenas a União e os Estados têm competência para legislar sobre matérias ambientais, pois, para o magistrado, o Município não poderia confrontar com a norma estadual já existente, que permite o uso de fogo na colheita da cana-de-açúcar (no caso, a Lei Estadual 11.241/2002).

No posicionamento doutrinário pode-se identificar a familiaridade do entendimento de Uadi Lammêgo com o pronunciado do magistrado:

(...) normas gerais são as que contêm declarações principiológicas, dirigidas aos legisladores, condicionando-lhes a ação legiferante. Recebem a adjetivação de "gerais" porque possuem um alcance maior, uma generalidade e abstração destacadas, se comparadas àquelas de normatividade de índole local. Consequência disso, elas não se prestam a detalhar minúcias, filigranas ou pormenores. As matérias que Ihes são afeitas não podem ser legisladas por outros entes federativos, exceto nos casos expressos de suplementação. (BULOS, 2005, p. 574).

O Desembargador Eros Piceli manifestou sua concordância ao posicionamento de Luiz Elias ao afirmar que o interesse peculiar do Município não deveria interferir na esfera da competência estadual, contrariando-a.

Nesta discussão, adentra-se aos princípios do regime federativo, invocando a separação dos poderes e as repartições das competências como fundamentos norteadores da Federação, como alerta Arthur Antônio Barbosa:

Nos demais votos no mesmo sentido, sempre é lembrado que tanto a separação dos poderes como a repartição de competências são fundamentais no regime federativo. Dessa forma, entendem que por a 
matéria da queimada estar disciplinada em Leis Estaduais, não competiria ao Município dispor de forma diversa. A vedação municipal não poderia afrontar assim, a permissão estabelecida pelo Estado, ente federal competente para legislar sobre o assunto. (BARBOSA, 2013, p. 84).

Walter de Almeida Guilherme, Desembargador, reforça seu posicionamento afirmando a inconstitucionalidade das leis proibitivas do Município, alegando que existem benefícios da queima da palha da cana-de-açúcar: a facilidade no corte do canavial e a eliminação de escorpiões e cobras.

Sob o argumento econômico, o Desembargador sustenta que as empresas sabem como administrar seus negócios, e se existisse outra maneira de se proceder a colheita da cana, sem que se precisasse efetuar a queimada dos canaviais e ainda assim manter o lucro das empresas do setor, tal solução já teria se desenvolvido pelos empresários, inclusive, questiona-se se haveria tecnologia suficiente para efetuar tal atividade sem a prática da queima.

Outros argumentos similares de cunho econômico também são relevantes na opinião de outros Desembargadores, como, por exemplo, a alegação de que proibir a queima da palha cana resultaria em um alto investimento das empresas que utilizam a cana-de-açúcar como matéria prima.

No aspecto social, os argumentos contrários à atuação municipal afirmam que a proibição das queimadas aumentaria consideravelmente 0 desemprego do trabalhador rural.

Muitos são os argumentos contra a interferência do Município nas matérias ambientais locais, invocando, principalmente, a falta de competência dos Municípios, ao considerar as leis por eles criadas como inconstitucionais, por contrariarem a Lei Estadual (ou Federal), mas existem argumentos favoráveis à possibilidade do Município exercer a atuação de protetor do meio ambiente local.

$\mathrm{Na} A D I$ no 163.415-0/4-00, que tratou do tema abordado nesta pesquisa, retratou o caso do Município de Cedral e a contagem dos votos dos Desembargadores foi de 13 votos vencedores contra a proibição da queima da cana-de-açúcar, contraposto a 11 votos vencidos de Desembargadores que eram favoráveis à edição de leis proibitivas do Município.

Os votos vencidos sustentam a constitucionalidade das leis municipais que proíbem a queima da palha da cana-de-açúcar, afirmando a autonomia do 
Município para suplementar a legislação estadual e federal e a melhor condição deste ente federativo para detectar agressões ao meio ambiente local, como afirma o Desembargador e professor Gilberto de Freitas:

\begin{abstract}
Considerando-se que os Municípios detêm melhores condições para detectar as agressões ao meio ambiente e adota com mais eficácia as medidas protetivas cabíveis, de inteira aplicação o princípio da subsidiariedade. Assim, conclui que é de interesse local do Município a questão relativa á queima da cana, razão pela qual afastou a inconstitucionalidade formal da lei municipal proibitiva. (FREITAS, 2007).
\end{abstract}

Além da premissa da autonomia dos Municípios, defensores da atuação legislativa deste ente federativo argumentam seu posicionamento fundamentados nos impactos ambientais causados pelas queimadas dos canaviais, ainda que os Desembargadores da corrente contrária hesitem em acreditar que tal prática seja responsável por efeitos altamente prejudiciais ao meio ambiente local.

Outro fator importante é a questão dos trabalhadores rurais, visto que as condições de trabalho oferecidas nos canaviais onde ocorre a queima da palha da cana-de-açúcar são péssimas. Logo, deveria se exigir que os empresários qualificassem a mão de obra e que melhorasse as condições de trabalho dos trabalhadores, pois só assim a indústria da cana-de-açúcar seria mais justa socialmente.

Segundo Camacho (2011) a questão do trabalho no campo no setor canavieiro é um dos mais importantes a ser discutido, pois:

(...) os boias-frias, empregados principalmente na produção de cana, tendo em vista que já foram registrados inclusive casos de morte por exaustão. Foram registrados, também, incidência de trabalho escravo e semiescravo, além da degradação ambiental que sempre acompanhou a produção da monocultura para a exportação. Os trabalhadores, na maioria das vezes, são submetidos a uma jornada fatigante que, quando não leva a morte, causam sérios problemas de saúde. Poucos têm os seus direitos trabalhistas regulamentados. (CAMACHO, 2011, pág. 14)

Questão também pesquisada por Beto (2007) quando ele afirma que:

A produção de cana no Brasil é historicamente conhecida pela superexploração do trabalho, destruição do meio ambiente e apropriação indevida de recursos públicos. As usinas se caracterizam pela concentração de terras para o monocultivo voltado à exportação. Utilizam em geral mão- 


\begin{abstract}
de-obra migrante, os bóias-frias, sem direitos trabalhistas regulamentados. Os trabalhadores são (mal) remunerados pela quantidade de cana cortada, e não pelo número de horas trabalhadas. $E$ ainda assim não têm controle sobre a pesagem do que produzem. Alguns chegam a cortar, obrigados, 15 toneladas por dia. Tamanho esforço causa sérios problemas de saúde, como câimbras e tendinites, afetando a coluna e os pés. A maioria das contratações se dá por intermediários (trabalho terceirizado) ou "gatos", arregimentadores de trabalho escravo ou semi-escravo. [...]. (BETTO, 2007, Não paginado).
\end{abstract}

A prática de queimar o canavial para facilitar a colheita só é viável aos empresários, pois tal ato barateia o corte manual, aumenta a produtividade e diminui bruscamente os custos, facilitando o transporte da cana.

Tal debate perdurou na apreciação do Poder Judiciário, sendo que, atualmente, a queima da palha da cana de açúcar é regulada pela Lei 11.241/2002 e pelo Decreto 47.700 , sendo que há um prazo de 30 anos previsto na legislação para que tal prática seja, gradativamente, substituída em sua totalidade.

O Protocolo Agroambiental firmado em 2007 representou o progresso da análise desta questão ambiental abordada. Neste acordo os produtores de cana do Estado de São Paulo se comprometeram a eliminar a prática das queimadas nos canaviais até 2014 nas áreas mecanizáveis e até 2017 nas áreas não mecanizáveis.

Posteriormente foi reconhecida no Supremo Tribunal Federal a repercussão geral do tema na Ação Direita de Inconstitucionalidade referente à Lei de Paulínia, sendo que a decisão dos magistrados afirmou a constitucionalidade da lei municipal.

Portanto, cabe ao Poder Judiciário resolver esta questão, com proporcionalidade, atendendo aos valores sociais e ambientais que devem nortear a Administração municipal. A decisão dos Desembargadores será muito importante, pois influenciará diversas ações de inconstitucionalidade referentes à queima da cana-de-açúcar que surgirão.

\title{
5. CONCLUSÃO
}

Com o grande avanço da cultura sucroalcooleira no Brasil, a preocupação sobre os impactos ambientais resultantes da queima da palha da cana-de-açúcar passou a ser uma relevante discussão em matéria ambiental. 
Ao desenvolver esta pesquisa, notou-se que os Municípios reagiram às agressões ambientais editando leis proibitivas que confrontavam com a Constituição Estadual, pois enquanto esta coibi a queima da palha da cana-de-açúcar, aquela autoriza tal prática.

$\mathrm{Na}$ repartição das competências da Constituição Federal de 1988, é conferida competência exclusiva que a Magna Carta aos Estados e à União, ou seja, compete a estes federativos a criação de normas gerais sobre matérias ambientais.

Porém, na questão da queima da palha da cana o Município passou a legislar e contrariar a Constituição Estadual do Estado de São Paulo que não proibia a queima. A reação dos Desembargadores que julgaram a causa, em sua maioria, entenderam que as leis do Município eram inconstitucionais.

Ponderando as questões debatidas neste trabalho, foi possível concluir que ainda que muitas vezes o Poder Judiciário entenda que há inconstitucionalidade formal nas leis editadas pelo Município, este ente federativo tem o dever constitucional de efetivar a proteção ambiental local, já que este está próximo à realidade da região, devendo legislar com coerência, objetivando o meio ambiente ecologicamente equilibrado aos munícipes.

\section{REFERÊNCIAS BIBLIOGRÁFICAS}

ANTUNES, João Francisco Gonçalves. AZANIA, Carlos Alberto Mathias. AZANIA, Andreia A. Padua Mathias. Impactos ambientais das queimadas de cana-de-açúcar. São Paulo: Cultivar, 2012.

BARBOSA, Arthur Antônio Tavares Moreira. A competência do Município para legislar sobre meio ambiente. Dissertação de Mestrado. Faculdade de Direito da Universidade de São Paulo, São Paulo, 2013.

BETTO, Frei. Necrocombustíveis. Disponível em: Acesso em out. 2007.

BORATTI, Larissa Verri, SCHMIDT Cintia, TEIXEIRA, Orci Paulino Bretanha. Política Municipal Ambiental - Perspectiva da gestão local do Meio Ambiente. Porto Alegre, Ed. Paixão, 2011.

BULOS, Uadi Lammêgo. Constituição Federal Anotada. 6. ed. Versão atualizada e ampliada até a Emenda Constitucional n 45/2004. São Paulo: Saraiva, 2005.

CAMACHO, Rodrigo Simão; CUBAS, Tiago; GONÇALVES, Elienai. Agrocombustíveis, soberania alimentar e políticas públicas: as disputas territoriais entre o agronegócio e o campesinato. Boletim DATALUTA: artigo do mês, p. 1-29, fev. 2011. Disponível em: http://www2.fct.unesp.br/nera/artigodomes/2artigodomes_2011.pdf 
GOES, Tarcízio. MARRA, Renner. A expansão da cana-de-açúcar e sua sustentabilidade. Disponível em: www.agencia.cnptia.embrapa.br. Acesso: 16. Abr. 2015.

GOLDEMBERG, J. Energia. In: TRIGUEIRO, A. Meio ambiente no século 21. Rio de Janeiro: Sextante, 2003.

JOVIANO, Carlos V. Martins. Expropriação, luta e resistência: A questão camponesa no bairro "Maquininha", Município de Dracena-SP, Dissertação de Mestrado, Dourados, UFGD, 2009.

KOHLHEPP, Gerd. Análise da situação da produção de etanol e biodiesel no Brasil. Disponível em: < http://www.scielo.br/scielo.php?script=sci arttext\&pid=S0103-40142010000100017>. Acesso:19 abr. 2015.

MARQUES, Tadeu Alcides. SASSO, Carlos Guilherme. SATO, Agnaldo Massao. SOUZA, Gustavo Maia. Queima do canavial: aspectos sobre a biomassa vegetal, fertilidade do solo e emissão de CO2 para a atmosfera. Disponível http://www.seer.ufu.br/index.php/biosciencejournal/article/viewFile/6796/4488>. Acesso: 12 abr. 2015.

MATTOS, K. M. da C., Valoração econômica dos impactos causados pela queima de cana-deaçúcar no meio ambiente. 2002. 125p. Tese (Doutor em Engenharia Ambiental) - Curso de PósGraduação em Engenharia Ambiental, USP, São Carlos, 2002.

OTTONI, Máximo Alessandro Mendes1. Etanol da cana-de-açúcar: consequências sociais e ambientais. Revista Multidisciplinar da UNIESP. Saber Acadêmico, n. 9, Montes Claros, 2010.

ROMERO, T. Etanol global: Brasil é referência em estudo para uso mundial do etanol. Disponível em: $\quad<w w w$. inovacaotecnologica.com.br/noticias/noticia.php?artigo=etanol-global-brasilreferenciaestudo-uso-mundial-etanol>. Acesso em 05 abr. 2015.

SILVA, José Afonso. Curso de Direito Constitucional Positivo. 13. ed. São Paulo: Malheiros, 2014.

SILVEIRA, Thiago Souza. Poluição atmosférica derivada de queimadas de cana-de-açúcar no Estado de São Paulo. Dissertação de Mestrado. Faculdade de Filosofia, Letras e Ciências Humanas da Universidade de São Paulo, São Paulo, 2014.

Supremo Tribunal Federal. Ministro reafirma competência de municípios para legislar sobre proteção ao meio ambiente. Disponível <http://www.stf.jus.br/portal/cms/verNoticiaDetalhe.asp?idConteudo=281851 >. Acesso 12 abr. 2015.

Planalto. Disponível em:<http://blog.planalto.gov.br/zoneamento-agroecologico-cana-de-acucarembrapa/>. Acesso: 14 abr. 2015.

THOMAZ JÚNIOR, Antonio. Por trás dos canaviais, os "nós" da cana: a relação capital $x$ trabalho e o movimento sindical dos trabalhadores na agroindústria canavieira paulista. São Paulo: Annablume/FAPESP, 2002. 